\title{
Black physicists matter
}

\author{
The persistent under-representation of Black physicists is a systemic problem that requires will, money and \\ long-term commitment to be solved.
}

$\mathrm{P}$ hysics has a proud history of internationalism. From the high-level international agreements that are the backbone of Big Science, to the individual experience that all practicing scientists have in working with colleagues from all manner of different backgrounds, many physicists certainly like to advocate that their work is independent of nationality, gender, class or ethnicity, and that what counts in physics - as in much of science - is the timeless universality of its main laws. Sub-atomic particles are blissfully unaware of our politics, for example, and the concepts and ideas we use to understand them don't care about walls and borders, anyway.

Paradoxically, it is perhaps for this very reason that physicists also find it difficult to talk about racism. It tends to put them in the awkward spot between the ideal that underpins their discipline and the practical and institutional reality that it is a part of.

Take the low number of Black physicists in the US, UK or, for that matter, any large-scale international collaboration. As for any other under-represented minority, the standard argument to excuse this state of affairs is to point out that it inevitably reflects a wider societal problem and that, while undoubtedly regrettable, it is effectively a pipeline problem that can be fixed over time.

It is high time that we recognize the issue is far deeper and more pernicious than that.

The senseless death of George Floyd in Minneapolis sparked widespread protests that have brought the issue of racism back to the fore internationally. While there is no doubt that factors such as the stress and anxieties brought about by the COVID19 lockdown, the entrenched economic inequalities that permeate American society, and police brutality that results from a shockingly over-the-top approach to law enforcement all played a role, the fundamental issue underpinning the Black Lives Matter movement is one of civil rights: yes, Black US citizens are equal in front of the eye of the law. No, for far too many of them the gap between the theory and the reality of this is far too large to ignore.

In academia, Black Lives Matter found expression in the '\#shutdownSTEM' strike, an initiative first announced by a group of physicists that had also been behind the Particles for Justice campaign against sexism in science a few years ago. By the time it was held on 10 June, it had rapidly spread throughout the science, technology, engineering and mathematics (STEM) communities both within and beyond the US. Along with all other Nature journals (and, indeed, many other academic publishers), Nature Physics supported this action.

\#shutdownSTEM asked the community "to commit to taking actions that will change the material circumstances of how Black lives are lived" and called on "people who are not Black to spend a day undertaking discussion and action that furthers this work". With this in mind, what can Nature Physics do in practice?

Firstly, we can reflect on the role we play in what is often an unwelcoming and exclusionary environment for Black physicists. As a high-profile journal, we acknowledge the convening power we have in giving physicists a platform one that, let's face it, is also a means to obtain funding and resource for future research projects.

Black physicists are currently less likely to find themselves in the position of even having the opportunity of being one of our authors, and we can therefore work to improve the diversity of the high-profile scientists that we publish. This can be achieved through the commentary and analysis that we commission, and by encouraging manuscript submissions from a wider range of sources. In this regard, our editors can undertake to visit and forge links with a greater variety of institutions when arranging their lab visits and conference itineraries in the future.

Secondly, we can work with physics societies to encourage more Black students to take up and pursue a career in physics. Organizations such as the American Institute of Physics (AIP) in the US and the Institute of Physics (IOP) in the UK have examined and attempted to address the issue of under-representation in the past, only to see their policy recommendations largely ignored by most academics and administrators. It is essential that the latest report by the AIP National Task Force to Elevate African American Representation in Undergraduate Physics \& Astronomy (TEAM-UP; https://go.nature. com/32TFg55) does not suffer the same fate.

Of the many factors TEAM-UP identify as critical for the success of Black students, three are worth mentioning in particular: a sense of belonging (to understand this, think of how Black stereotypes and the impostor phenomenon can exacerbate a sense of not belonging); a physics identity (in other words, enabling Black students to perceive themselves, and be perceived by others, as future physicists); and finally, personal support to offset financial burdens and stress. On a wider, structural level, it is therefore essential to recognize that the solution to this problem requires putting money where our mouth is.

Finally, we can do more to highlight work from low-income countries. The issue of racism is not confined to the US, and there are many physics institutions around the world, such as the Abdus Salam International Centre for Theoretical Physics (ICTP) and the African School of Fundamental Physics and Applications, with insufficient recognition and funding for the work that they do.

Physicists are not exempt from society, they are a part of it. And so we too must grapple with the harrowing trauma of slavery as it continues to echo through the generations. A reappraisal of the roots of modern science is therefore inevitable: we attribute many of the ideals that we hold dearest to the Enlightenment - the age of reason, liberty and progress. Yet we still tend to ignore what lies in its shadow: the age of European empires, of plunder and of exploitation.

Racism is not an issue we have paid sufficient attention to in the past. The benefit of bringing it out into the open and addressing the issue directly will be an altogether healthier and inclusive scientific environment.

Published online: 4 August 2020 https://doi.org/10.1038/s41567-020-1010-X 